University of Louisville

ThinkIR: The University of Louisville's Institutional Repository

Faculty Scholarship

$4-2015$

\title{
Disclosure during private prayer as a mediator between prayer type and mental health in an adult Christian sample.
}

\author{
Stephanie Winkeljohn Black \\ University of Louisville \\ Patrick Pössel \\ University of Louisville \\ Benjamin Jeppsen \\ Augustana College - Sioux Falls \\ Annie C. Bjerg \\ University of Louisville \\ Don T. Wooldridge \\ University of Louisville
}

Follow this and additional works at: https://ir.library.louisville.edu/faculty

Part of the Counseling Psychology Commons

\section{Original Publication Information}

Winkeljohn Black, Stephanie, Patrick Pössel, Benjamin D. Jeppsen, Annie C. Bjerg and Don T. Wooldridge. "Disclosure during Private Prayer as a Mediator between Prayer Type and Mental Health in an Adult Christian Sample." 2015. Journal of Religion and Health 54(2): 540-553.

The final publication is available at Springer via https://doi.org/10.1007/s10943-014-9840-4

This Article is brought to you for free and open access by ThinkIR: The University of Louisville's Institutional Repository. It has been accepted for inclusion in Faculty Scholarship by an authorized administrator of ThinkIR: The University of Louisville's Institutional Repository. For more information, please contact thinkir@louisville.edu. 
Disclosure during Private Prayer as a Mediator between Prayer Type and Mental Health in an Adult Christian Sample 


\begin{abstract}
According to Poloma and Pendleton's (1991) prayer model there are four prayer types (colloquial, meditative, petitionary, and ritual), all of which have varying associations with mental health. However, few studies have examined what mechanisms explain these associations. The literature demonstrates that disclosing distressing information can improve mental health. Thus, the current study examined self-disclosure as a mediating variable between Poloma and Pendleton's (1991) prayer types and mental health. It was hypothesized that self-disclosure would mediate the association between prayer types involving meaningful communication with God (colloquial and meditative prayer types) and mental health and would not mediate associations between petitionary and ritual prayer types and mental health. This cross-sectional, online study analyzed data from praying Christian adults $(N=296)$ to test the hypotheses. As predicted, selfdisclosure mediated the positive associations between colloquial and meditative prayer types and mental health. Self-disclosure was not associated with petitionary or ritual prayer and therefore did not mediate the relationships of these prayer types with mental health, as expected. Petitionary prayer had a negative relationship to mental health, while ritual prayer had a positive relationship to mental health. The results indicate that selfdisclosure is an important mediator to consider when investigating the associations between private prayer and mental health.
\end{abstract}

Keywords: private prayer, disclosure, mental health 
Contemporary definitions of prayer denote that prayer involves an act of communication with $\mathrm{God}^{1}$ (for a review see Spilka \& Ladd, 2013). Many have considered private prayer's (hereafter simply referred to as “prayer”) positive relationship to an individual's mental health. For example, prayer is positively associated with life satisfaction, optimism, and psychological well-being in adult, predominately Christian samples (Maltby, Lewis, \& Day, 1999; Poloma \& Pendleton, 1989, 1991). Additionally, prayer is negatively related to symptoms of anxiety, depression, and negative affect (Koenig, 2007; Poloma \& Pendleton, 1989, 1991). However, little work has been done to investigate what mechanisms explain prayer's relationship with mental health. Moreover, the literature also demonstrates that the content, or type, of prayer determines whether it has a positive or negative association with mental health (e.g., Maltby et al., 1999; Poloma \& Pendleton, 1989). In other words, while there is an established, positive association between prayer and mental health, the underlying mechanisms to explain the association have not been identified, nor have the mechanisms been explored while tracking the type of prayer an individual most often uses.

\section{Prayer Type}

Poloma and Pendleton (1991) created a model to determine what elements comprise private prayer. The model includes prayer frequency, prayer experience (e.g., insight, inspiration), and four prayer types: colloquial, meditative, petitionary, and ritual. Colloquial prayer involves talking to God in one's own words, such as asking God for guidance. Meditative prayer involves observing and feeling the presence of God and listening for a response. Petitionary prayer involves asking God for material things for

\footnotetext{
${ }^{1}$ Because this study looks at a Christian sample, the term "God" is used throughout the article, in keeping with the language used in the self-report measures and in the literature (e.g., Froese \& Bader, 2007).
} 
oneself or friends, and ritual prayer involves recitation of prayers, such as reading from a book of prayers.

Research has demonstrated that each of the prayer types have different associations with mental health. Colloquial prayer has a positive relationship with happiness (Poloma \& Pendleton, 1991) and a negative relationship with anxiety and depression (Maltby et al., 1999). Meditative prayer has a positive relationship with wellbeing (Poloma \& Pendleton, 1991) and a negative relationship with anxiety, depression, and social dysfunction (Maltby et al., 1999). However, the associations between petitionary and ritual prayers with mental health are less consistent. Poloma and Gallup (1991) found that petitionary prayer is associated with more mental health problems, while others found no such association (Maltby et al., 1999). Whittington and Scher (2010) found that a type of prayer in Laird, Snyder, Rapoff, and Green's (2004) model, supplication, had a negative association with life satisfaction. Whittington and Scher (2010) noted in their study that Laird's supplication prayer type was very similar in content to Poloma and Pendleton's (1989) petitionary prayer. Finally, Poloma and Pendleton (1991) found ritual prayer to have a positive relationship with negative affect while Maltby and associates (1999) found this prayer type to have a negative relationship with anxiety, depression, and social dysfunction. It is worth noting that all of the above studies' samples were comprised primarily of American, Christian adult participants.

Despite differences in each prayer type's association with mental health, some prayer types share particular qualities. Colloquial, meditative, and petitionary prayers involve communication with God. In colloquial prayer, the pray-er (the person praying) engages in a conversation with God to which they are praying. Meditative prayer 
involves an "intimacy” with God in which the pray-er feels and listens for God's presence and is engaged in a thoughtful and mindful "personal relationship" (pp. 79-80, Poloma \& Pendleton, 1991). In petitionary prayer, the pray-er initiates communication by asking God for a material item. However, the communication occurring during petitionary prayer does not, by definition, require the pray-er reflecting on their internal state. Moreover, a national survey conducted by Poloma and Gallup (1991) shows that some people consider petitionary prayer to be "childish" or less mature because the prayer expects God to "intervene" in daily life. Thus, communication in petitionary prayer may relate less meaningfully to the pray-er's current affect or level of well-being as compared to the communication of a pray-er engaging in colloquial or meditative prayer. Ritual prayer, according to Poloma and Pendleton's (1991) definition, does not include any communication with God. The prayer types' differences regarding the presence or quality of communication are intriguing when considered within the context of each prayer type's association to mental health. A clearer understanding of the purpose or mechanism of communication during particular prayer types may explain the relationship between prayer type and mental health.

\section{Self-Disclosure}

Self-disclosure is the communicative process of sharing personal thoughts and feelings with another (VandeCreek, Janus, Pennebaker, \& Binau, 2002). Individuals who engage in emotional disclosure of distressing thoughts and feelings are more likely to experience positive mental health compared to individuals who do not engage in selfdisclosure (Pennebaker, 1999; Pennebaker, Mayne, \& Francis, 1997; Saxena \& Mehrotra, 2010). Chaudoir and Fisher (2010) stated that the process of disclosure begins with the 
discloser forming a goal(s) for disclosing something. That is, the discloser considers and anticipates how disclosing material will alter their situation (e.g., connect to someone on a deeper level, to "test" a new confidant). This goal formation involves thinking critically about one's beliefs about the information they wish to disclose. In other words, Chaudoir and Fisher (2010) propose that the mental processing of disclosed material is essential. This conclusion is supported by research on written disclosure demonstrating that individuals' mental health improves based on the extent to which they are able to mentally process the disclosed information (Pennebaker, 1995).

Traditionally, self-disclosure is conceptualized as occurring between two persons. However, some researchers have begun to investigate the possibility that self-disclosure might occur between a person and God (e.g., Bennett, 2005; VandeCreek et al., 2002). It should be noted that there might be a difference between disclosing to another person and disclosing to God. However, Froese and Bader (2007) analyzed American Christian adult self-reports about how they see God and found that participants had diverse ideas about their image of God. Thus, analyzing how God's image might influence disclosure is beyond the scope of this initial investigation into disclosure.

Two studies conducted linguistic analyses comparing written self-disclosures in an essay format and in prayers. Both found that written self-disclosure essays and prayers involving self-disclosure were lexically similar, indicating that, at the very least, the actual words used to disclose are similar regardless if an individual is disclosing to another person or to God (Bennett, 2005; VandeCreek et al., 2002). Both studies found that prayer disclosures contained more positive emotion compared to the written disclosures. Moreover, Bennett (2005) found significant mental health benefits for both 
the participants who disclosed to God and participants who wrote out their disclosures. VandeCreek and colleagues' study, however, used a sample of seminary students (all Christian, primarily European American, and both male and female). Thus, the level of devotion and understanding of theology in this sample is likely different from the overall American Christian population. Nevertheless, Bennett (2005) found similar results with college students, indicating at least some generalizability of the results.

Though researchers have begun investigating how prayers may include disclosures with the benefits to the discloser's mental health, many things remain unclear. In particular, the type of prayer used may impact whether disclosure occurs for the prayer. This difference in disclosures among prayer types may explain, in part, why different prayer types have different mental health outcomes.

\section{Current Study}

Based on the considerations outlined above, the current study explored selfdisclosure as a possible mediator between prayer type and mental health. The literature demonstrates that colloquial and meditative prayers are positively associated with better mental health (Maltby et al., 1999; Poloma \& Pendleton, 1991), but possible reasons behind this positive association have not been empirically studied. It has been established that disclosing stressful events to another is related to positive mental health (Pennebaker, 1999; Pennebaker, Mayne, \& Francis, 1997; Saxena \& Mehrotra, 2010). Thus, it can be hypothesized that when an individual discloses something to God s/he experiences a decrease in psychological distress. During colloquial prayer, the pray-er has the opportunity to thoughtfully disclose information to God in their words. Moreover, since it involves a more casual conversation (compared to ritual prayer, for 
example, which typically involves formalized or structured phrases), there is an opportunity for the pray-er to process their decision and goals for disclosure while praying about the distressing event. Meditative prayer is defined as more passive than colloquial prayer, involving the pray-er's mindfulness of their thoughts and feelings. As noted by Chaudoir and Fisher (2010), this awareness of one's internal states is a part of the decision-making process of whether to disclose information. Thus, disclosure could begin to occur during meditative prayer. Therefore, it was hypothesized that the positive relationship of colloquial prayer and meditative prayer with mental health would be mediated by self-disclosure to God.

Findings demonstrate that petitionary prayer has either a negative relationship with mental health (Poloma \& Pendleton, 1991) or no significant relationship with mental health at all (Maltby et al., 1999). It was theorized that the petitionary pray-er does not reflect on their feelings in a way that facilitates disclosure to God. The negative or lack of relationship between mental health and petitionary prayer can be explained by the pray-er's lack of meaningful disclosure. Thus, it was predicted that there would be no significant relationship between petitionary prayer and self-disclosure to God. Based on previous research, it also was expected that petitionary prayer would have either a negative or no relationship to mental health. It was hypothesized that self-disclosure would not mediate the relationship between petitionary prayer and mental health. Finally, ritual prayer, by definition, does not have to require communication with God. Thus, it was predicted that there would be no significant relationship between ritual prayer and self-disclosure. Based on the literature, it was expected that there would be either a positive or no relationship between ritual prayer and mental health. Following 
these predictions, it was hypothesized that self-disclosure would not mediate the relationship between ritual prayer and mental health.

\section{Method}

\section{Participants}

Christian participants were recruited for a cross-sectional online study (see Procedure; $\mathrm{N}=296 ; 77.0 \%$ female; mean age $=36.10$ years, $S D=18.21$ years; age range $=18$ to 83 years). Most of the participants identified as European American (88.8\%), followed by 5.8\% African American, 2.0\% mixed race/ethnicity, 1.0\% Asian American, 0.7\% Hispanic/Latino, and $0.3 \%$ Native American. The majority of the participants identified as non-denominational (33.8\%, followed by $19.6 \%$ Catholic, $17.6 \%$ Methodist, 11.5\% Church of Jesus Christ of Latter Day Saints, 9.8\% Baptist, 2.0\% Episcopal, 1.4\% Pentecostal, $1.0 \%$ Lutheran, $0.7 \%$ Orthodox, 0.7\% Seventh Day Adventist, and 0.3\% Jehovah's Witness).

\section{Measures}

Prayer type. Prayer type was measured with the 16-item, self-report Prayer Types Scale (Poloma \& Pendleton, 1989). The items ask participants how often they engage in various prayer behaviors, with all items answerable on a 7-point Likert scale (never-several times a day). The scale measures the frequency of behaviors for the four identified prayer types: colloquial, meditative, petitionary, and ritual. The internal consistency for all four subscales ranged from adequate to strong for this sample (Cronbach's alpha for Colloquial Prayer $=.91$; Meditative Prayer $=.93$; Petitionary Prayer $=.90 ;$ Ritual Prayer $=.59)$. This scale was developed in an American adult 
sample (Poloma \& Pendleton, 1989) and has been used in Christian samples since then (Maltby et al., 1999).

The colloquial and meditative prayer subscales had a very strong positive correlation $(\mathrm{p} r=.617 p<.001)$ when controlling for petitionary and ritual prayer subscales. Based on this high correlation, a principle components analysis with varimax rotation was performed on the Prayer scale items to determine where the current data loaded on four factors as in Poloma and Pendleton's (1989) model. Analyses revealed that all of the items loaded on three factors rather than four. The petitionary and ritual types subscales remained intact as in the original model (Poloma \& Pendleton, 1989). However, all of the colloquial and meditative items loaded onto a single factor. Therefore, the latter two subscales were combined into one for all further analyses (Cronbach's alpha for the combined scale was high, .95). ${ }^{2}$ This combination of subscales does not interfere with the hypotheses of the study, wherein it was predicted that the Distress Disclosure Index (see below; Kahn \& Hessling, 2001) would mediate the association between both of the prayer subscales (colloquial and meditative) that are combined into one factor and the Profile of Mood States - Short Form (see below; Shacham, 1983).

Self-disclosure. The Distress-Disclosure Index (DDI; Kahn \& Hessling, 2001) contains 12 items and measured participants' tendency to disclose stressful information to another person. For this study, the items were modified to measure one's level of disclosure to God (Appendix A). For example, the original item, "When I feel upset, I

\footnotetext{
${ }^{2}$ The analyses were also performed with all four of the prayer subscales separated, and findings were consistent between the three and four-factor models in terms of the significance and direction of the mediation findings. The findings are available from the first author for review.
} 
usually confide in my friends" was rewritten to be "When I feel upset, I usually confide in God." One item ("I try to find people to talk with about my problems") could not be adapted for the current study and was dropped from the scale. Each statement is answered on a 5-point Likert scale (strongly agree-strongly disagree). A confirmatory factor analysis was conducted to ensure that the modified items load on a single factor, as was shown with the original scale (Kahn, Hucke, Bradley, Glinski, Malak, 2011). All remaining, modified items had significant loadings onto the factor, indicating that the modified scale successfully measures one construct (i.e., disclosure) ${ }^{3}$. The internal consistency for this sample was strong (Cronbach's alpha $=.90)$.

Mental health. The Profile of Mood States-Short Form (POMS-SF; Schacham, 1983) is a common measure of overall mental health. The self-report questionnaire has 37 items; each item is an affective word (e.g., angry, tense, energetic, etc.) that participants rate on a 5-point Likert scale to demonstrate how often they have experienced the feeling in the past two weeks (not at all-extremely). Scores are calculated by summing the negative affect items (e.g., tense) and the positive affect items (e.g., energetic) separately and then subtracting the sum of the positive affect items from the sum of the negative affect items. A high score on the measure indicates low mental health. The internal consistency for this sample was strong (Cronbach's alpha $=.95)$. The POMS has been used previously in studies exploring religiosity and prayer (e.g., Hills, Paice, Cameron, \& Shott, 2005; Johnson et al., 2011).

\section{Procedure}

Participants were recruited through social networking sites, undergraduate courses in psychology at two large universities (one western, one southern), and email lists

\footnotetext{
${ }^{3}$ The results of the factor analysis can be requested from the first author.
} 
relating to the study of religion or psychology (e.g., listservs for the American

Psychological Association Division 36 - Psychology of Religion, American Association for Christian Counseling, Christian Association for Psychological Studies, and Society for Christian Psychology). Additionally, announcements were posted on the website of a Baptist Theological Seminary and a sports fan discussion board at a large western university. All participants completed the measures through the web-based survey program Surveymonkey. The Institutional Review Board at the University of Louisville approved the study.

\section{Data Analysis}

Partial correlations were calculated for all variables in the model in order to control for shared variance among the variables. Most participants frequently used a combination of the different prayer types. Thus, controlling for the shared variance among prayer types ensured that only the unique contribution of a prayer type's variance to the DDI or POMS was considered. Additionally, ethnicity, sex, and age were entered into the model as control variables, given that there is some literature indicating that these demographics influence disclosure and mental health (e.g., Dindia, 1992; Thomsen, Mehlsen, Viidik, Sommerlund, \& Zachariae, 2005). While some demographic variables had clear associations to the study's variables (e.g., sex and disclosure) based on previous research, other possible associations were less clear (e.g., prayer types and demographic variables). Thus, all three demographic variables were initially entered as control variables for all of the study variables, and then the model was analyzed and optimized.

Next, the final optimized model's goodness of fit to the data was tested with $\chi^{2}$ (Kline, 2005; Ullman, 1996). Statistically nonsignificant values of $\chi^{2}$ mean that the data fit the model well. Nonetheless, this measure is sensitive to sample size. Additional goodness of fit 
indices were evaluated to determine model fit, including the Comparitive Fit Index (CFI; Bentler, 1990), Tucker-Lewis Index (TLI; Tucker \& Lewis, 1973), and root mean squared of the residuals (RMSEA; Steiger \& Lind, 1980). CFI and TLI values of 1.00 demonstrate a perfect model fit to the data, values of $\geq .95$ demonstrate good model fit, and values of $\geq .90$ are considered acceptable (Hu \& Bentler, 1999). An RMSEA value of .00 demonstrates a perfect model fit to the data, and values of $<.05$ are considered a good model fit, though values of $<.08$ are as acceptable (Hu \& Bentler, 1999).

Next, Hayes and Preacher's (2011) method for mediation analysis with multiple independent variables was followed to determine whether the DDI mediated any associations between the prayer types and the POMS. This method allowed each prayer type's relationship to the POMS through the DDI to be analyzed while controlling for the other three prayer types. To test whether self-disclosure mediated the relationships between each prayer type and mental health, the direct, total, and indirect effects between the four prayer types and mental health were evaluated. Based upon Preacher and Hayes (2008), only the independent effects are needed to determine whether mediation is

present. Bootstrap confidence intervals (CI: 95\%) were calculated, and Zhao, Lynch, and Chen's (2010) guidelines for interpreting mediation types were used to analyze the effects.

\section{Results}

Descriptive statistics, correlations, and partial correlations among the variables, with colloquial and meditative prayer types shown separately and combined, are provided in Table 1. Indirect effects between the prayer scales and POMS are provided in Table 2.

The original mediation model included the control variables sex, age, and ethnicity. Pathways (or correlations, when appropriate) initially connected each of the 
three control variables to all remaining variables in the model. The model was analyzed and the pathways involving control variables were examined for significance. Nonsignificant pathways (or correlations) between each of the control variables and remaining variables were removed, thus optimizing the model. In the final optimized model (Figure 1) the prayer types were controlled for sex and age, the DDI was controlled for sex and ethnicity, and the POMS was controlled for age and sex (Figure 1). The final optimized model had an excellent model fit $\left(\chi^{2}(11)=11.563, p=.397, \mathrm{CFI}\right.$ (.998), TLI (.996), RMSEA (.014), indicating that the final mediation model fit the data well.

Regarding the mediation analyses, the indirect effects from the combined colloquial/meditative prayer subscale to the POMS were significant and in the expected direction. This indicates that - as predicted - the DDI mediated the association between the combined colloquial/meditative prayer types and the POMS (Zhao et al., 2010). There were no significant indirect effects from either the petitionary prayer or ritual prayer types to the POMS, indicating that the DDI did not mediate the association from petitionary and ritual prayer to the POMS. There were no significant indirect effects from either the petitionary prayer or ritual prayer types to the POMS. However, there was a significant partial correlation in the expected direction from petitionary prayer to the POMS, indicating that - also as predicted - the DDI did not mediate the association from petitionary prayer to the POMS. Additionally, there was a significant, negative partial correlation from ritual prayer to the POMS. This indicated that - as predicted the DDI did not mediate the association from ritual prayer to the POMS.

\section{Discussion}


The literature shows that Poloma and Pendleton's (1991) four prayer types have different associations with mental health (Maltby et al., 1999; Poloma \& Pendleton, 1991). However, studies have not examined what mechanisms might explain these differing relationships between prayer types and mental health. This study hypothesized that self-disclosure, which lessens negative mental health symptoms (Pennebaker, 1999; Pennebaker, Mayne, \& Francis, 1997; Saxena \& Mehrotra, 2010), would mediate the relationship between some prayer types and mental health. This hypothesis was based upon the notion that two of the prayer types (colloquial prayer and meditative prayer) involve introspective and meaningful communication wherein the pray-ers examine their internal state while communicating and potentially disclosing to a God. Petitionary prayer includes communication with God, but does not involve the same introspective quality, and is considered a less mature prayer type by some (Poloma \& Gallup, 1991). Thus, meaningful disclosure during petitionary prayer is unlikely. By definition, ritual prayer does not require communication (Poloma \& Pendleton, 1991). Thus, it was hypothesized that neither petitionary prayer nor ritual prayer are associated with selfdisclosure. It was also hypothesized that self-disclosure would not mediate the relationships of petitionary prayer and ritual prayer with mental health. Finally, it was expected that petitionary prayer would have either a negative or no relationship to mental health, while ritual prayer would have either a positive or no relationship with mental health.

Initial analyses demonstrated that Poloma and Pendleton's (1989) instrument separated into three prayer types, rather than four, in the current sample. Colloquial and meditative prayer types were combined into one construct and all subsequent analyses 
examine the new, three factor/prayer type structure. Because self-disclosure was hypothesized to mediate the associations between both colloquial and meditative prayer types and mental health, the use of this three-factor/prayer type structure did not interfere with the study's hypotheses. In addition, analyses with the four original scales found the same pattern of results that analyses with the combined colloquial/meditative prayer subscale found. Moreover, the final model fit for the three-factor model with control variables demonstrated an excellent fit to the data, indicating that, at least for the current sample, this model was an acceptable alternative to the four-factor model.

The mediation analyses supported the hypotheses. Self-disclosure mediated the relationship between colloquial prayer and mental health, as well as the relationship between meditative prayer and mental health. Neither petitionary prayer nor ritual prayer was associated with self-disclosure. Consequently, self-disclosure did not mediate the relationship between petitionary prayer and mental health, nor did it mediate the relationship between ritual prayer and mental health. Moreover, petitionary prayer had a negative relationship to mental health and ritual prayer had a positive relationship to mental health, as expected. Overall, although disclosure to God helps explain the relationship between colloquial and meditative prayer types and mental health, it does not explain the relationship between petitionary and ritual prayer types and mental health.

These findings become more compelling when conceptualizing prayer as a means of communication. Baesler's $(1999,2003)$ relational prayer theory (RPT) asserts that as a pray-er engages in more prayer, they will develop a close relationship with God. This relationship to God will then impact the pray-er's prayer, leading them to engage in more God-oriented, rather than self-oriented, prayer. The pray-er also will begin to view 
prayer as two-way communication (i.e., God talks back) instead of one-way communication. Chaudior and Fisher's (2010) model of disclosure stipulates that the "success" of disclosure (i.e., whether the disclos-er finds the process helpful), depends partly on how the recipient reacts to the disclosure. In prayer, this might involve waiting for God's reaction to the disclosed information. This would require prayer types allowing for two-way communication, rather than prayer types that might be limited to one-way communication (e.g., petitionary prayer). Of Poloma and Pendleton's (1989) prayer types, it seems that meditative prayer involves two-way communication, while colloquial and ritual prayer could be either one-way or two-way, and petitionary prayer appears to be almost entirely one-way in nature. Following this line of thought, it might be that disclosure as measured in the current study represented three things: disclosure, communication type (i.e., one-way or two-way), and relationship to God. The finding that colloquial and meditative prayer's positive association to mental health is mediated by disclosure supports this notion - both prayer types can involve two-way communication and might indicate that the pray-er has a closer relationship to God than pray-ers who rely less on these prayer types. All of these factors might be mediating the association between colloquial and meditative prayer and mental health. Conversely, disclosure did not mediate the association between petitionary prayer, a type of one-way communication, and mental health. By these standards and the current findings, ritual prayer could be considered non-communicative, though additional study needs to be done to draw such heavy conclusions.

Before conclusions can be drawn from this study, the limitations must be addressed. First, the study was cross-sectional, so no conclusions can be drawn regarding 
the causality of found associations among the variables found in this study. However, given that this was the first study to investigate disclosure as a mechanism to explain prayer's association to mental health, this cross-sectional study still contributes to the literature. Second, there are differences among the study's measures that should be considered. The DDI measures specific prayer content, whereas the Prayer Types Scale measures the frequency of prayer content. The inclusion of additional measures regarding prayer disclosure and prayer content could bolster the internal validity of this investigation. Third, the current study did not control for how people view God. Froese and Bader $(2007,2008)$ have noted the diversity in images of God, even (or perhaps, especially) among individuals living in the United States. Froese and Bader (2007) contend that these diverse images of God may account for much diversity in other oriented constructs, such as prayer and political ideology. Thus, further studies would strengthen the current findings by accounting for participants' images of God. Finally, there were two issues surrounding the prayer type instrument. The internal consistency of the ritual prayer subscale was lower than preferred; analyses involving ritual prayer should therefore be interpreted cautiously. The original factor structure of Poloma and Pendleton's (1989) Prayer Type measure was not upheld based upon an exploratory factor analysis performed on the current sample (for a more in-depth discussion, see Breslin et al., 2010). However, when the mediation analyses were performed with four separate prayer subscales, the same mediation pattern was found (i.e., disclosure mediated the association between both colloquial prayer and meditative prayer and mental health). The use of a three-factor model, rather than the original four-factor model, indicates that the results should be interpreted with caution. The three-factor 
structure could be a result of the small sample, especially when compared to Poloma and Gallup's (1989) findings that were based on major national surveys, which almost certainly were more representative of American Christianity. Additionally, the majority of the current sample was comprised of participants identifying as European American, and the entire sample was comprised of participants identifying as Christian. Therefore, the results of the current should not be generalized to pray-ers of other ethnicities or religious affiliations. Purposive sampling techniques could increase the overall generalizability of results and to present the opportunity to conduct between-group analyses to better understand how various identities (e.g., religious identity) may interact with prayer behaviors. Thus, future studies should obtain a more diverse sample to determine whether these findings hold true for other ethnic and religious groups. Researchers who contemplate replicating the current study may want to consider several moderating variables when replicating this mediation model. Future studies with larger sample sizes should consider the possibility of multigroup analyses to determine whether the mediation model remains stable across different groups (i.e., by sex, gender, or ethnicity). This would allow for more detailed conclusions regarding how prayer and disclosure might differ based on the pray-er's demographic characteristics. Further evaluations of self-disclosure as a mechanism explaining the association between mental health and prayer may benefit from exploring other prayer models to see if self-disclosure as a mediator is upheld with different prayer conceptualizations and models, as Poloma and Pendleton's (1989) prayer typology is one of many models of prayer types (e.g., Ladd \& Spilka's 2002, 2006 model; Laird et al.’s 2004 model). 
Summarized, self-disclosure, as predicted, mediated the relationships between colloquial and meditative prayer types and mental health. As hypothesized, selfdisclosure was not associated with petitionary and ritual prayer and, therefore, did not mediate the relationships of petitionary and ritual prayer types with mental health. If these findings can be replicated, preferably in longitudinal and experimental studies, selfdisclosure might be seen as explanation for why some prayer types are not always associated with an improvement in mental health. Thus, disclosure to God seems to be one mechanism through which we can explain the positive relationships between some types of prayer and mental health (e.g., Maltby et al., 1999; Poloma \& Pendleton, 1991). Further investigations regarding how the pray-er sees their communication with God (i.e., as one-way or two-way) and the pray-er's perceived relationship to God could continue to elaborate on how specifically this mechanism might impact a pray-er's well-being. One possibility to strengthen these findings is to test this model with various prayer typologies that address communication, such as Lee, Poloma, and Post's new proposal (2013) on prayer as communication. Such information would aid faith groups in helping their members develop a health-promoting, positive prayer experience and would help mental health professionals to conceptualize further their religious and spiritual client's prayer behaviors as adaptive or maladaptive, in the latter case helping the client to consider alternative ways of engaging in prayer behaviors. 


\section{References}

Baesler, E.J. (1999). A model of interpersonal Christian prayer. The Journal of Communication and Religion, 22, 40-64.

Baesler, E.J. (2003). Theoretical explorations and empirical investigations of communication and prayer. Lewiston, New York: Edwin Mellen Press.

Bennett, P.R. (2005). Prayers about traumatic experiences as self-disclosure to God: Implications for health and well-being. Dissertation Abstracts International: Section B: The Sciences and Engineering, 67, 1746.

Bentler, P. M. (1990). Comparative fit indexes in structural models. Psychological Bulletin, 107, 238-246. doi: 10.1037/0033-2909.107.2.238

Breslin, M.J., \& Lewis, C.A. (2010). A psychometric evaluation of Poloma and Pendleton's (1991) measure of prayer experience. Journal of Beliefs \& Values: Studies in Religion \& Education, 31, 93-96.

Chaudoir, S. R., \& Fisher, J. D. (2010). The disclosure processes model: Understanding disclosure decision-making and post-disclosure outcomes among people living with a concealable stigmatized identity. Psychological Bulletin, 136, 236-256.

Dindia, K., \& Allen, M. (1992). Sex differences in self-disclosure: A meta-analysis. Psychological Bulletin, 112, 106-124.

Froese, P. \& Bader, C.D. (2007). God in America: Why theology is not simply the concern of philosophers. Journal for the Scientific Study of Religion, 46, 465481. 
Froese, P., \& Bader, C. (2008). Unraveling religious worldviews: The relationship between images of God and political ideology in a cross-cultural analysis. The Sociological Quarterly, 49, 689-718.

Hayes, A. F., \& Preacher, K. J. (2011). Indirect and direct effects of a multicategorical causal agent in statistical mediation analysis.

Hills, J., Paice, J.A., Cameron, J.R., \& Shott, S. (2005). Spirituality and distress in palliative care consultation. Journal of Palliative Medicine, 8, 782-788.

Hu, L. \& Bentler, P. M. (1999). Cut-off criteria for fit indexes in covariance structure analysis: Conventional criteria versus new alternatives. Structural Equation Modeling, 6, 1-55. doi: 10.1080/10705519909540118

Johnson, K.S., Tulsky, J.A., Hays, J.C., Arnold, R.M., Olsen, M.L., Lindquist, J.H., et al. (2011). Which domains of spirituality are associated with anxiety and depression in patients with advanced illness? Journal of General Internal Medicine, 26, 751758.

Kahn, J.H., \& Hessling, R.M. (2001). Measuring the tendency to conceal versus disclosure psychological distress. Journal of Social and Clinical Psychology, 20, 41-65.

Kahn, J. H., Hucke, B. E., Bradley, A. M., Glinski, A. J., \& Malak, B. L. (2011). The Distress Disclosure Index: A research review and multitrait-multimethod examination. Journal of Counseling Psychology, 1-16.

Kline, R. B. (2005). Principals and practice of structural equation modeling ( $2^{\text {nd }}$ ed.). New York, NY: Guilford. 
Koenig, H. G. (2007). Religion and depression in older medical inpatients. American Journal of Geriatric Psychiatry, 15, 282-291.

Ladd, K. L., \& Spilka, B. (2002). Inward, outward, and upward: Cognitive aspects of prayer. Journal for the Scientific Study of Religion, 41, 475-484.

Ladd, K. L., \& Spilka, B. (2006). Inward, outward, and upward: Scale reliability and validation. Journal for the Scientific Study of Religion, 45, 233-251.

Laird, S.P., Snyder, C.R., Rapoff, M.A., Green, S. (2004). Measuring private prayer: Development, validation, and clinical application of a multidimensional prayer inventory. International Journal for the Psychology of Religion, 14, 251-272.

Lee, M.T., Poloma, M.M., \& Post, S.G. (2013). The Heart of Religion: Spiritual Empowerment, Benevolence, and the Experience of God's Love. Oxford University Press, New York.

Maltby, J., Lewis, C. A., \& Day, L. (1999). Religious orientation and mental health: The role of the frequency of personal prayer. British Journal of Health Psychology, 4, 363-378.

Pennebaker, J. W. (1995). Emotion, disclosure, and health: An overview. In J. W. Pennebaker (Ed.), Emotion, disclosure, \& health. (pp. 3-10). Washington, DC: American Psychological Association.

Pennebaker, J.W. (1999). Psychological factors influencing the reporting of physical symptoms. In A.A. Stone, J.S. Turkkan, C.A. Bachrach, J.B. Jobe, H.S. Kurtzman, and V.S. Cain (Eds), The science of self-report: Implications for research and practice (pp 299-316). Mahwah, NJ: Erlbaum Publishers. 
Pennebaker, J.W., Mayne, T.J., \& Francis, M.E. (1997). Linguistic predictors of adaptive bereavement. Journal of Personality and Social Psychology, 72, 863-871.

Poloma, M. M., \& Gallup, G. H. (1991). Varieties of prayer. A survey report. Philadelphia, PA: Trinity Press.

Poloma, M. M., \& Pendleton, B. F. (1989). Exploring types of prayer and the quality of life. Review of Religious Research, 31, 46-53.

Poloma, M. M., \& Pendleton, B. F. (1991). The effects of prayer and prayer experiences on measures of general well-being. Journal of Psychology \& Theology, 19, 71-83.

Preacher, K. J., \& Hayes, A. F. (2008). Asymptotic and resampling strategies for assessing and comparing indirect effects in multiple mediator models. Behavior Research Methods, 40, 879-891.

Saxena, P., \& Mehrotra, S. (2010). Emotional disclosure in day-to-day living and subjective well being. Psychological Studies, 55, 208-218.

Shacham, S. (1983). A shortened version of the Profile of Mood States. Journal of Personality Assessment, 47, 305-306.

Spilka, B., \& Ladd, K.L. (2013). The psychology of prayer: A scientific approach. New York: The Guilford Press.

Steiger, J. H. \& Lind, J. M. (1980, May). Statistically based tests for the number of common factors. Paper presented at the Psychometrika Society meeting, Iowa City, IA.

Thomsen, D.K., Mehlsen, M.Y., Viidik, A., Sommerlund, B., \& Zachariae, R. (2005). Age and gender differences in negative affect - Is there a role for emotion regulation? Personality and Individual Differences, 38, 1935-1946. 
Tucker, L. R. \& Lewis, C. (1973). The reliability coefficient for maximum likelihood factor analysis. Psychometrika, 38, 1-10. doi: 10.1007/BF02291170

VandeCreek, L., Janus, M., Pennebaker, J. W., Binau, B. (2002). Praying about difficult experiences as self-disclosure to God. International Journal for the Psychology of Religion, 12, 29-39.

Ullman, J. B. (1996). Structural equation modeling. In B. Tabachnick \& L. Fidell (Eds.), Using multivariate statistics ( $3^{\text {rd }}$ ed., pp. $\left.709-812\right)$. New York, NY: HarperCollins.

Whittington, B.L., \& Scher, S.J. (2010). Prayer and subjective well-being: An examination of six different types of prayer. The International Journal for the Psychology of Religion, 20, 59-68.

Zhao, X., Lynch, J. G., \& Chen, Q. (2010). Reconsidering Baron and Kenny: Myths and truths about mediation analysis. Journal of Consumer Research, 37, 197-206. 
Table 1

Descriptive Statistics and Partial Correlations among the Variables

\begin{tabular}{|c|c|c|c|c|c|c|}
\hline & DDI & $\begin{array}{c}\text { Colloquial } \\
\text { Prayer }\end{array}$ & $\begin{array}{c}\text { Meditative } \\
\text { Prayer }\end{array}$ & $\begin{array}{c}\text { Coll/Med } \\
\text { Prayer }\end{array}$ & $\begin{array}{c}\text { Petitionary } \\
\text { Prayer }\end{array}$ & $\begin{array}{l}\text { Ritual } \\
\text { Prayer }\end{array}$ \\
\hline DDI & -- & & & & & \\
\hline Colloquial Prayer & $.281 * *$ & -- & & & & \\
\hline Meditative Prayer & $.218 * *$ & $.617 * * *$ & -- & & & \\
\hline Coll/Med Prayer & $.599 * * *$ & -- & -- & -- & & \\
\hline Petitionary Prayer & .031 & $.171 * * *$ & $.122 *$ & $.430^{* * * *}$ & -- & \\
\hline Ritual Prayer & .00 & .072 & .074 & $.225^{* * *}$ & -.039 & -- \\
\hline POMS & $-.282^{* *}$ & -.037 & -.036 & $-.239 * * *$ & .164 & $-.162^{* *}$ \\
\hline Mean & 44.04 & 28.78 & 20.88 & 49.60 & 5.79 & 4.59 \\
\hline Standard Deviation & 7.40 & 8.45 & 8.42 & 15.93 & 3.08 & 2.83 \\
\hline
\end{tabular}

Note. ${ }^{* * *} p<.001{ }^{* *} p<.01 ; * p<.05 . \mathrm{DDI}=$ Distress Disclosure Index; Colloquial

Prayer $=$ Colloquial Prayer Subscale; Meditative Prayer = Meditative Prayer Subscale;

Coll/Med Prayer $=$ Colloquial and Meditative Prayer Subscales; Petitionary Prayer $=$

Petitionary Prayer Subscale; Ritual Prayer $=$ Ritual Prayer Subscale; POMS = Profile of Mood States. 
Table 2

95\% Confidence Intervals for Indirect Effects through the DDI

\begin{tabular}{lccc}
\hline & Effects & Lower CI & Upper CI \\
\hline Coll/Med Prayer- POMS & -.171 & -.377 & -.087 \\
Petitionary Prayer - POMS & -.011 & -.249 & .091 \\
Ritual Prayer- POMS & -.004 & -.200 & .133 \\
Coll/Med Prayer - DDI & .000 & .000 & .000 \\
Petitionary Prayer - DDI & .000 & .000 & .000 \\
Ritual Prayer - DDI & .000 & .000 & .000 \\
DDI - POMS & .000 & .000 & .000 \\
\hline
\end{tabular}

Note. ${ }^{*} p<.01 ; * p<.05 . \mathrm{DDI}=$ Distress Disclosure Index; Coll/Med Prayer $=$

Colloquial and Meditative Prayer Subscales; Petitionary Prayer = Petitionary Prayer

Subscale; Ritual Prayer $=$ Ritual Prayer Subscale; POMS = Profile of Mood States. 


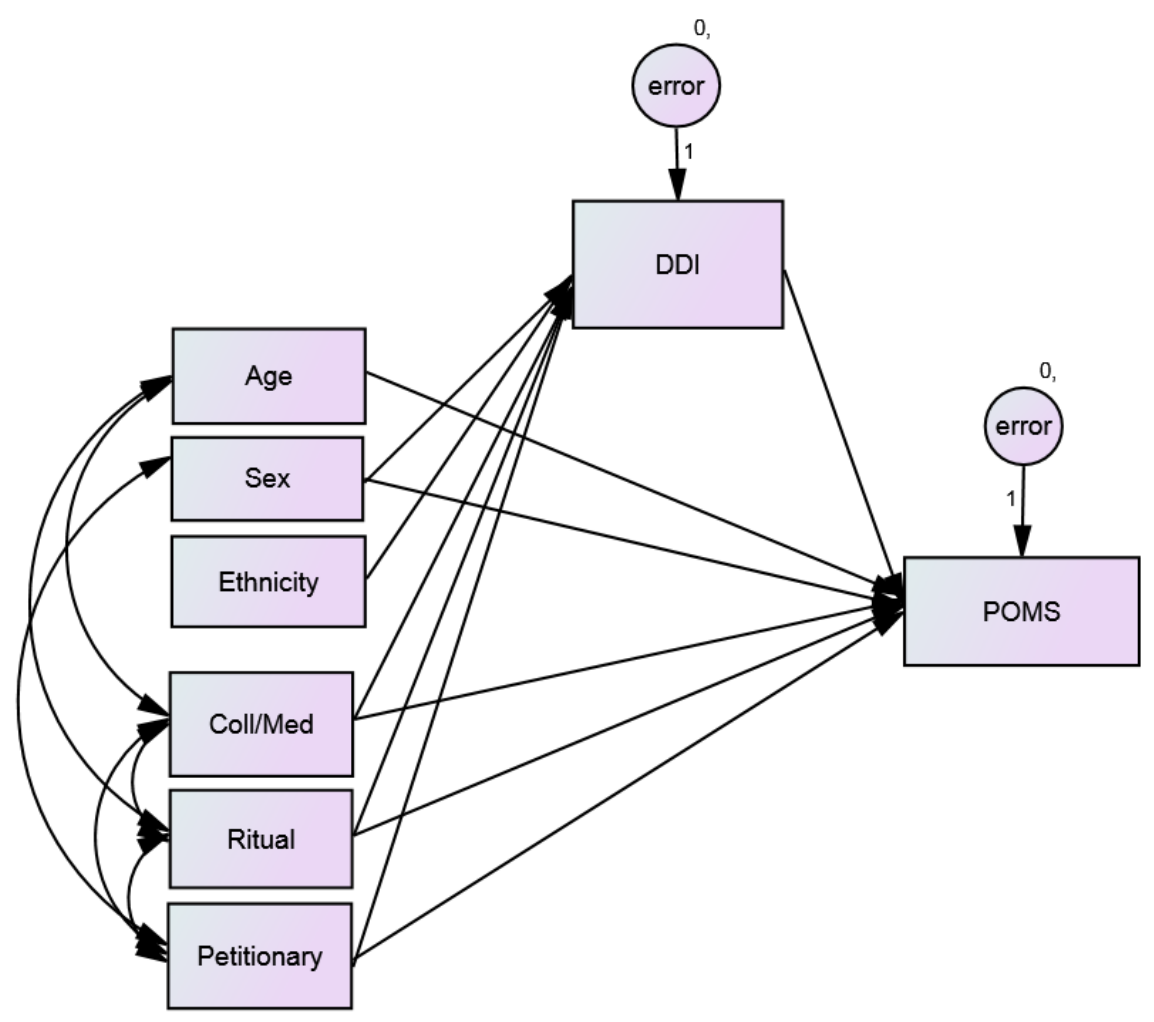

Figure 1

Final Optimized Model

DDI $=$ Distress Disclosure Index; Coll/Med $=$ Colloquial and Meditative Prayer Subscales; Petitionary = Petitionary Prayer Subscale; Ritual = Ritual Prayer Subscale; POMS $=$ Profile of Mood States. Age, sex, and ethnicity were entered as control variables. 
Appendix A - Revised Distress Disclosure Index items (Kahn \& Hessling, 2001)

1. When I feel upset, I usually confide in God.

2. I prefer not to pray about my problems to God.

3. When something unpleasant happens to me, I often pray about it.

4. I typically don't pray about things that upset me.

5. When I feel depressed or sad, I tend to keep those feelings to myself.

6. When I am in a bad mood, I pray about it.

7. If I have a bad day, the last thing I want to do is pray about it.

8. I rarely pray when I am having a problem.

9. When I am distressed I don't pray.

10. I usually pray when I am in a bad mood.

11. I am willing to tell God about my distressing thoughts.

Note. Items 2, 4, 5, 7, 8, 9 are reverse scored 